\title{
Drug Susceptibility Testing of Mycobacterium tuberculosis by the Broth Microdilution Method with 7H9 Broth
}

\author{
Ahmet Yilmaz Coban ${ }^{+}$, Asuman Birinci, Bora Ekinci, Belma Durupinar
}

Department of Microbiology and Clinical Microbiology, Medical School, Ondokuz Mayis University, 55139 Samsun, Turkey

In this study, we have evaluated the broth microdilution method (BMM) for susceptibility testing of Mycobacterium tuberculosis. A total of 43 clinical isolates of M. tuberculosis and H37Rv as a control strain were studied. All isolates were tested by the proportion method and the BMM for isoniazid (INH), rifampicin (RIF), streptomycin (STR), and ethambutol (ETM). The proportion method was carried out according to the National Committee for Clinical Laboratory Standards (NCCLS) on Löwenstein-Jensen (LJ) medium. The BMM was carried out using 7 H9 broth with 96 well-plates. All strains were tested at 3.2-0.05 $\mu \mathrm{g} / \mathrm{ml}, 16-0.25 \mu \mathrm{g} / \mathrm{ml}, 32-0.5 \mu \mathrm{g} / \mathrm{ml}$, and 32-0.5 $\mu \mathrm{g} / \mathrm{ml}$ concentrations for INH, RIF, STR, and ETM, respectively. When the BMM was compared with the proportion method, sensitivity was 100, 100, 96.9, and 90.2\%, while specificity was 100, 85.7, 90.9, and 100\% for INH, RIF, STR, and ETM, respectively. The plates were examined 7, 10, 14, and 21 days after incubation. The majority of the result were obtained at 14th days after incubation, while the proportion method result were ended in 21-28 days. According to our results, it may be suggested that the BMM is suitable for early determining of multidrug-resistance-M. tuberculosis strains in developed or developing countries.

Key words: Mycobacterium tuberculosis - broth microdilution method - susceptibility testing

Tuberculosis is an important public health problem in developed and especially in developing countries. The incidence of multidrug-resistant (MDR) Mycobacterium tuberculosis has increased in recent years. Mycobacterial cultures and susceptibility testing must be rapidly concluded for effective treatment and control of the disease (Zapata et al. 1999).

The two methods most commonly used for susceptibility testing of $M$. tuberculosis include the proportion method performed on Löwenstein-Jensen medium (LJ) and Middlebrook 7H10-11 agar, and the Bactec TB 460 system (Becton Dickinson Microbiology System, Cockeysville, MD, US). The proportion method requires 3 weeks of incubation. The Bactec TB system uses a broth medium containing radiolabeled palmitic acid substrate and results can be reported in 4-7 days, but it is labor-intensive, expensive, and generates radioactive waste (Zapata et al. 1999, NCCLS 2002, Birinci et al. 2002).

A number of new methods for drug susceptibility testing of M. tuberculosis have been described over the last decade, including mycobacteria growth indicator tube (MGIT), the E test, and Alamar blue (Yajko et al. 1995, Wagner \& Mills 1996, Walters \& Hanna 1996, Collins \& Franzblau 1997, Birinci et al. 2002).

Recently, it has been reported that the newly developed microdilution test method for M. tuberculosis is a practical, rapid, quantitative, nonradiometric alternative for the determination of minimum inhibitory concentrations (MICs) in clinical mycobacteriology laboratories

${ }^{+}$Corresponding author. Fax: +90-362-457.6041. E-mail: noahmet@yahoo.com

Received 25 August 2003

Accepted 12 December 2003
(Yamane et al. 1998, 1999, Leite et al. 2000). In addition, it has been disclosed that the broth microdilution method is very close to the Center for Disease Control and Prevention (CDC), Atlanta, US (1994) guidelines, except for isolation and identification of M. tuberculosis (Yamane et al. 1999).

Our aim was to compare the proportion method with $\mathrm{LJ}$ medium and the broth microdilution method (BMM) for susceptibility testing of $43 \mathrm{M}$. tuberculosis clinical isolates.

\section{MATERIALS AND METHODS}

Strains - A total of 43 clinical isolates and the H37Rv standard strain were tested by the proportion method and the broth microdilution method. All clinical isolates and standard isolate were freshly grown on LJ medium. All clinical isolates were defined as M. tuberculosis according to growth rates, pigmentation properties of colonies, nitrate reduction, and niacin accumulation tests (Koneman et al. 1997).

\section{Susceptibility testing}

Inoculum preparation - Freshly grown colonies from LJ medium were transferred to a tube containing 3-4 ml phosphate buffered saline and 6 to 9 sterile glass beads. Tubes were vigorously agitated on a vortex mixer and clumps were allowed to settle for $30 \mathrm{~min}$. The supernatants were transferred to sterile tubes. This supernatants were then adjusted with phosphate buffer saline to equal the density of $0.5 \mathrm{McF}$ arland standard for use as the standard inoculum in the BMM and adjusted to equal the density of $1.0 \mathrm{McF}$ arland for use as the standard inoculum for the proportion method (NCCLS 2002).

The proportion method procedure - The proportion method was performed as described by the National Committee for Clinical Laboratory Standards (NCCLS 2002). Antimycobacterial drugs were adjusted in the LJ medium 
to final concentrations of $0.2-1 \mu \mathrm{g} / \mathrm{ml}$ for isoniazid (INH), $40 \mu \mathrm{g} / \mathrm{ml}$ for rifampicin (RIF), $4 \mu \mathrm{g} / \mathrm{ml}$ for streptomycin (STR), and $2 \mu \mathrm{g} / \mathrm{ml}$ for ethambutol (ETM). One hundred microliter of prepared bacterial inoculum was inoculated on LJ medium, containing or not drug for test or as a control, followed by incubation at $37^{\circ} \mathrm{C}$ for $21-28$ days. Resistance was defined as growth on drug containing tubes greater than $1 \%$ of the growth of drug free control medium for INH, RIF, ETM, and 10\% for STR (Leite et al. 2000, NCCLS 2002).

The BMM - The BMM was performed in 96-well microtitre plates with U-shapped wells as described by Leite et al. (2000). Wells were filled with $0.1 \mathrm{ml}$ amounts of Middlebrook 7H9 broth, supplemented with oleic acid, albumin, dextrose and, catalase (OADC) enrichment. The stock suspensions of drugs were diluted in Middlebrook $7 \mathrm{H} 9$ broth and seven serial dilution for each drugs and plates were stored at $-25^{\circ} \mathrm{C}$ until use. The antibiotics gradient was 3.2-0.05 $\mu \mathrm{g} / \mathrm{ml}$ for INH, $16-0.25 \mu \mathrm{g} / \mathrm{ml}$ for RIF and, $32-0.5 \mu \mathrm{g} / \mathrm{ml}$ for STR and ETM.

Each well was inoculated with $5 \mu \mathrm{l}$ of $0.5 \mathrm{McF}$ arland standard bacterial suspension. A well without antimycobacterial agents was also inoculated with $10^{-2}$ dilution of $0.5 \mathrm{McF}$ arland standard as a growth control. The plates were sealed, placed in plastic bags and incubated at $37^{\circ} \mathrm{C}$ for 21 days in a moisturized incubator.

MIC was defined as the lowest drug concentration that exhibited no growth by visual reading, and the strains were considered susceptible for each drug, if their MICs were below or equal to the critical concentration (Heifets 1991). The results were evaluated after 7, 10, 14, and 21 days and they were compared with those obtained by the proportion method using the critical concentration of drugs.

\section{RESULTS}

The results are summarized in the Table and plates were evaluated at $7,10,14$, and 21 days according to the growth on control well. Discrepancies between observed results were retested.
The agreement was $96.5 \%$ between the BMM and the proportion method (166 of 172 susceptibility testing). Sensitivities were 100, 100, 96.9, and 90.2\% for INH, RIF, STR, and ETM, respectively. Specificities were 100, 85.7, 90.9, and $100 \%$ for INH, RIF, STR, and ETM, respectively. Positive predictive values were 100, 97.3, 96.9, and $100 \%$ for INH, RIF, STR, and ETM, respectively. Negative predictive values were $100,100,90.9$, and $33.3 \%$ for INH, RIF, STR, and ETM, respectively. The sensitivity, specificity, positive predictive value and negative predictive values for a total of 172 antibiotic susceptibility tests were 96.5 , $93.1,98.6$, and $84.4 \%$, respectively. Results of both tests were in $100 \%$ agreement with INH results. The results of the BMM were available in 7,10, and 14 days for 1 isolate, 8 isolates, and 34 isolates, respectively.

\section{DISCUSSION}

Early detection of MDR-M. tuberculosis strains is important for control of tuberculosis. Recently, new methods for drug susceptibility testing of M. tuberculosis have been described, including MGIT, the E test, Alamar blue, and nucleic acid base methods (Walters \& Hanna 1996, Wagner \& Mills 1996, Collins \& Franzblau 1997, Birinci et al. 2002). However, some of these methods are expensive and require special equipment (Leite et al. 2000). In this study, we compared the proportion method with the BMM and found no statistically significant differences in susceptibility testing results between the BMM and the proportion method ( $96.5 \%$ agreement). The results of the BMM were available in 10 to 14 days.

Leite et al. (2000) compared the BMM with the proportion method and they found that sensitivity was $100 \%$ for all drugs and specificities were $91,100,98,96$, and $85 \%$ for INH, RIF, STR, ETM, and pyrazinamide, respectively. The results were available in 14-20 days. Yamane et al. (1998, 1999) reported that the BMM for M. tuberculosis is a practical, rapid, quantitative, nonradiometric alternative for the determination of MICs in clinical mycobacteriology laboratories. Wallace et al. (1986) used the BMM for slowly growing myobacterial species (including M. tuberculo-

TABLE

The results of susceptibility testing by the broth microdilution method (BMM) and the proportion method

\begin{tabular}{|c|c|c|c|c|c|c|c|}
\hline \multirow[b]{2}{*}{ Drug } & \multirow[b]{2}{*}{$\begin{array}{l}\text { Results of } \\
\text { proportion } \\
\text { method }\end{array}$} & \multicolumn{6}{|c|}{ The BMM results } \\
\hline & & $\begin{array}{l}\mathrm{Nr} \text { of } \\
\text { resistant } \\
\text { strains }\end{array}$ & $\begin{array}{c}\mathrm{Nr} \text { of } \\
\text { susceptible } \\
\text { strains }\end{array}$ & $\begin{array}{c}\% \\
\text { sensitivity }\end{array}$ & $\begin{array}{c}\% \\
\text { specificity }\end{array}$ & $\begin{array}{c}\% \\
\text { positive predictive } \\
\text { value }\end{array}$ & $\begin{array}{c}\% \\
\text { negative predictive } \\
\text { value }\end{array}$ \\
\hline \multirow[t]{2}{*}{ INH } & Resistant & 9 & 0 & \multirow[t]{2}{*}{100} & \multirow[t]{2}{*}{100} & \multirow[t]{2}{*}{100} & \multirow[t]{2}{*}{100} \\
\hline & Susceptible & 0 & 34 & & & & \\
\hline \multirow[t]{2}{*}{ RIF } & Resistant & 6 & 1 & \multirow[t]{2}{*}{100} & \multirow[t]{2}{*}{85.7} & \multirow[t]{2}{*}{97.3} & \multirow[t]{2}{*}{100} \\
\hline & Susceptible & 0 & 36 & & & & \\
\hline \multirow[t]{2}{*}{ STR } & Resistant & 10 & 1 & \multirow[t]{2}{*}{96.9} & \multirow[t]{2}{*}{90.9} & \multirow[t]{2}{*}{96.9} & \multirow[t]{2}{*}{90.9} \\
\hline & Susceptible & 1 & 31 & & & & \\
\hline \multirow[t]{2}{*}{ EMB } & Resistant & 2 & 0 & \multirow[t]{2}{*}{90.2} & \multirow[t]{2}{*}{100} & \multirow[t]{2}{*}{100} & \multirow[t]{2}{*}{33.3} \\
\hline & Susceptible & 4 & 37 & & & & \\
\hline
\end{tabular}

INH: isoniazid; RIF: rifampicin; STR: streptomycin; ETM: ethambutol 
sis) using 7H9 broth. They reported that the BMM was suitable for testing of multiple drugs at multiple concentrations. Higa et al. (2002) reported that both of the proportion method and the BMM were highly precise for susceptibility testing of $M$. tuberculosis complex.

The main goal of this study is to determine susceptible or resistant $M$. tuberculosis isolates rather than to determine MIC values by using the BMM as alternative method. In conclusion, our results do not show statistically significant differences between the BMM and the proportion method. The results of the BMM can be reported faster (10-14 days) than the proportion method (21-28 days). In addition, the BMM allows testing of multiple drugs at multiple concentrations, requiring no special or expensive equipment nor the use of radioactive material. It may thus be suggested that the BMM is suitable for early determining of MDR-M. tuberculosis strains in developed or developing countries.

\section{REFERENCES}

Birinci A, Coban AY, Ekinci B, Durupinar B 2002. Comparison of the proportion method with Mycobacteria Growth Indicator Tube and E-test for susceptibility testing of Mycobacterium tuberculosis. Mem Inst Oswaldo Cruz 97: 351352.

Collins LA, Franzblau SG 1997. Microplate Alamar blue assay versus BACTEC 460 system for high-throughput screening of compounds against Mycobacterium tuberculosis and Mycobacterium avium. Antimicrob Agents Chemother 41: 1004-1009.

Heifets LG 1991. Drug Susceptibility in the Chemotherapy of Mycobacterial Infections, CRC Press, Boca Raton, Ann Arbor, Boston, London.

Higa M, Saitoh H, Yamane N, Nakasone I, Miyagi C 2002. Interpretive compatibility of antimycobacterial susceptibility for Mycobacterium tuberculosis determined by proportion test method on egg-based Ogawa media and broth microdilution test, Broth MIC MTB (Abstract). Kekkaku 77: 61-66.

Koneman EW, Allen SD, Janda WM, Schreckenberger PC, Winn WC 1997. Diagnostic Microbiology, 4th ed., JB Lippincott Co, Philadelphia.
Leite CQF, Beretta ALRZ, Anno IS, Telles MAS 2000. Standartization of broth microdilution method for Mycobacterium tuberculosis. Mem Inst Oswaldo Cruz 95: 127129.

NCCLS-National Committee for Clinical Laboratory Standards 2002. Antimycobacterial susceptibility testing for Mycobacterium tuberculosis. Tentative standard M24-T, NCCLS, Villanova, PA.

Wagner M, Mills K 1996. Testing of Mycobacterium tuberculosis susceptibility to ethambutol, isoniazid, rifampin and streptomycin by using E test. J Clin Microbiol 34: 16721676.

Wallace RJ, Nash DR, Steele LC, Steingrube V 1986. Susceptibility testing of slowly growing myocabacteria by a microdilution MIC method with 7H9 broth. J Clin Microbiol 24: 976-981.

Walters SB, Hanna BA 1996. Testing of susceptibility of Mycobacterium tuberculosis to isoniazid and rifampin by Mycobacterium Growth Indicator Tube method. J Clin Microbiol 34: 1565-1567.

Yajko DM, Madej JJ, Lancaster MV, Sanders CA, Cawthon VL, Gee B, Babst A, Hadley WK 1995. Colorimetric method for determining MICs of antimicrobial agents for Mycobacterium tuberculosis. J Clin Microbiol 33: 2324-2327.

Yamane N 1999. Mycobacteria-methods to meet the CDC guidelines (Abstract). Rinsho Byori 47: 539-546.

Yamane N, Ichiyama S, Kawahara S, Iinuma Y, Saitoh H, Shimojima M, Udagawa H, Nakasone I 1999. Multicenter evaluation of broth microdilution test, BrothMIC MTB, to determine minimum inhibitory concentrations (MICs) of antimicrobial agents for Mycobacterium tuberculosis-evaluation of interlaboratory precision and interpretive compatibility with agar proportion method (Abstract). Rinsho Byori 47: 754-766.

Yamane N, Nakasone I, Saitoh H, Kaneda M, Shimojima M, Yamashita K, Toyoda K, Okazawa Y 1998. Evaluation of a newly developed broth microdilution test method to determine minimum inhibitory concentrations (MICs) of antimicrobial agents for mycobacteria (Abstract). Rinsho Byori 46: 719-727.

Zapata P, Arbeloa M, Aznar J 1999. Evaluation of Mycobacteria Growth Indicator Tube (MGIT) for drug susceptibility testing of Mycobacterium tuberculosis isolated from clinical specimens. Clin Microbiol Infect 5: 227-230. 